\title{
The effect of network convergence on digital culture industry: Model construction of network industrial economics and empirical study on China
}

Panqiang Niu

Department of Journalism and Communication, Shanghai University, China.

Email:panqiangniu@163.com

Anang Masduki

Department of Communication Studies, Universitas Ahmad Dahlan, Indonesia.

Email: anang.masduki@comm.uad.ac.id

Xigen Li

Department of Journalism and Communication, Shanghai University, China.

Email: lixigen@shu.edu.cn

Filosa Gita Sukmono

Department of Communication Studies, Universitas Muhammadiyah Yogyakarta, Indonesia Email: filosa@umy.ac.id

\section{Abstract}

This paper constructs the model of network economics to study the effect of different levels of network convergence on the digital culture industry. Then uses 
regression models and mediating effect models to test the effect mechanism of network convergence on the digital culture industry of China. This paper used panel data to conduct an empirical study. The data in this paper were quarterly. The time range was from the first quarter of 2009 to the third quarter of 2013 for 19 quarters. The three data types in econometrics are time series data, crosssectional data, and panel data. The main conclusions are as follows. Network convergence brings positive policy effects and adverse capital effects. The impact of network convergence on firm performance of the digital culture industry is not statistically significant, and this effect also has no indirect effects on the test of mediating effect. However, network convergence indirectly leads to the reduction of operating costs of the digital culture industry. The indirect effect is brought by the chain mediating effect of policy effect and capital effect. The study could provide a reference for other countries and regions. Meanwhile, it can be used to analyze the impact of different media convergence on digital industries.

Keywords: Network, Convergence, Digital, Culture, Industry

\section{INTRODUCTION}

Network convergence is defined as the efficient coexistence of the following three networks within a single network: video transmission, a telephone network, and data communication. In recent years, network convergence has significantly progressed. Network convergence is called tri-network convergence in China. The executive meeting of the State Council of China confirmed the tri-network convergence program in 2010 (The State Council, 2010): two-way access between radio $\&$ television and telecommunications was attempted from 2010 to 2012.

The digital culture industry (short for DCI) belongs to the I.T. industry's information transfer and intermediary sector. This paper considers that the digital culture industry is based on digital, multimedia, and network technologies and uses information and other resources to create, develop, distribute and consume products and information services. The digital culture industries include digital film and television production, digital games, digital animation, interactive entertainment, three-dimensional images, digital learning, digital publishing, digital collection, digital performance, network services, content software, etc. The rapid growth of DCI is the result of the development of many factors. Previous studies posited that the reason is mainly attributed to 
two aspects. One aspect is the advancement of technology of the DCI itself, e.g., digital processing and digital storage (Tsai et al., 2008). The other aspect is the advancements in information systems infrastructure, e.g., the innovation of network technology (Yong \& So, 2008) and network convergence. The digital culture industry is one related sector with network convergence. In a general sense, network convergence will transform the digital culture industry's industrial chain and value chain. However, few theoretical discussions on the effect mechanism of network convergence on the digital culture industry. Therefore, this paper will conduct an in-depth study of this issue. Nowadays the 14th five year plan of China clearly proposes to develop the digital economy in the post COVID-19 era, the research of this paper has a certain reference value for policy-making of China, and also has a certain reference significance for other countries.

The paper is organized as follows. Section 2 is a literature review and theoretical basis. The paper builds a network industrial economics model in Section 3. A theoretical framework and an empirical study based on Chinese panel data are done in Section 4. Section 5 is the discussion.

\section{LITERATURE REVIEW}

\section{A. Literature Review and Theoretical Basis}

a. Effect of network convergence on digital culture industry growth

Convergence is not a newly conceived notion. McLuhan (1964) argued as early as the 1960s that telecommunications networks and information broadcasting would jointly create a 'global village.' Farber and Baran were the first to address the convergence issue in 1977 (Lind, 2004). Convergence was defined in various ways in the literature (Ovum, 1999). It can be present at three different, although interrelated, levels: the technological level, the structural level, and the services and markets level (Iosifidis, 2002). Obviously, in this paper, convergence refers only to network convergence.

The institution and policy of network convergence are essential content of study. For example, Liu (2013) studies regulatory challenges and policy recommendations on China's triple-network convergence plan; Wu \& Leung (2012) explores the implementation of tri-network convergence in China from a new institutional analysis. 
There are some comparative studies on the effect of network convergence. First, network convergence can promote the endogenous growth of the industry and form emerging industries by technical dissemination and realize the external expansion of the sector through industry restructuring (Hacklin et al., 2005; Brusoni \& Pavitt, 2003). For example, the convergence of three information industries (telecommunication, cable television, and internet) created the internet protocol television industry. Second, network convergence forms a competitive market structure and competitive synergetic relationship. In the background of network convergence, the publishing, photoelectric and internet sectors all enable reading. Therefore, competition occurs among enterprises within an industry and enterprises across different industries. Third, network convergence will guide the upgrading of industry and promote the parallel development of industries. The emerging sectors that result from network convergence have high elasticity of demand and increased profitability. This trait will lead to the transfer of production factors from other sectors to emerging industries. Therefore, network convergence will result in the recession of the traditional culture industry and the growth of the digital culture industry.

Network convergence is expected to serve as an enabler for new business models, and a means to reduce operations and management costs, and a platform for faster deployment of new multimedia applications (Rost et al., 2011). It is generally agreed that the process of convergence between telecommunications, I.T., and broadcasting through its technological, organizational, and market/service aspects has a far-reaching influence on the sectors involved and on future socioeconomic settings. The converged network is a critical player in e-business and the next-generation applications currently being developed for the growing digital economy (Moyer \& Umar, 2001). Technological, economic, and social drivers have caused the telecommunications market to converge, with boundaries between diverging technologies, industries, and services becoming blurred (Ioannis, 2009; Miyazaki \& Giraldo, 2015). Convergence will bring new business models and supply chain structures for the digital culture industry (Francis, 2009). Network convergence will broaden the communication channels of the digital culture industry, stimulate its market demand, and promote its 
upgrade (Gao, 2014).

There is also some research to focus on network convergence in specific digital culture industry sectors. In the studies on the impact of network convergence on digital publishing, network convergence will promote industrial convergence and provide new publishing channels and terminals for digital publishing (Tang \& Xiao, 2013). In network games, network games may become a catalyst between the internet and broadcasting networks and serve the public through mobile platforms and terminals (Qin, 2014). Regarding digital music, the favorable effect of network convergence is that it facilitates the communication of digital music on each platform (Song, 2014) and extends more personalized music services.

As shown in the literature review above, there have been basic studies on network convergence in the digital culture industry. These related studies have made some progress. However, the research has some limitations. At first, most studies have not formed a systematic theory or mechanism on the effect of network convergence. Secondly, network convergence will not occur overnight, and it is a process rather than an event (Hu, 2007). Network convergence has various degrees (Kim, 2010; Whitt, 2004; Patel, 1992; Napoli, 2001). However, many related studies did not offer a dynamic perspective to analyze network convergence in other industries. Thus, this paper aims to investigate the effect of different levels of network convergence on the digital culture industry and the effect mechanism.

b. Theoretical basis for analyzing the effect of network convergence

This paper will use the economics of network industries, neoinstitutional economics, and new institutional economics to construct the theoretical basis of the effect mechanism of network convergence on the digital culture industry.

The research object of network industries economics is infrastructure industries with a networkstructure, such as communication networks and transportation networks. The economics of network industries studies incentive regulation and market competition (Shy, 2001). The government's goal to promote network convergence is to build a competitive market structure for the communication industry. The communication network is the infrastructure of the 
digital culture industry, and consumers must consume the digital culture industry through a communication network. According to the economics of network industries economics, the market structure of the communication industry is different before and after network convergence, and this difference is reflected in the price and service quality of the communication industry. At the same time, this difference will be delivered to the digital culture industry, which will affect the price, supply, and demand of digital content products. Based on the model of network industries economics constructed, this paper will first study the effect of network convergence on the price, supply, and demand of digital content enterprises in change from one network to the convergence of three networks. According to the economics of network industries, the following paper will study network convergence on price, supply, demand, product quality, consumer utility, etc.

Although network industry economics is suitable for studying the influence of network convergence, the main body of network industry economics is still a continuation of the research paradigm of neoclassical economics and takes price as the critical factor. The research of neoclassical economics is based on the given parameters such as preference, institution, etc. These hypotheses have some defects in studying the influence of network convergence. Under the influence of network convergence, the institution is changing, and policy regulation is an essential factor that affects the in-depth development of network convergence. In order to promote the development of network convergence, it is necessary to reform some institutions or policies (Liu, 2013). Therefore, this paper needs to use neo-institutional economics and new institutional economics to make up for the deficiency of the network industries economics model.

Neo-institutional economics emphasizes the incompleteness of the market role and highlights the role of government intervention in the economy and practical policies. Therefore, to adapt to the development of network convergence, the digital culture industry needs the intervention of government policy, which provides a theoretical basis for the government to make a series of industrial policies to develop the digital culture industry. The study of new institutional economics is relatively more in-depth and specific. According to the theory of enterprise boundaries in new institutional economics, the 
effect of network convergence on the digital culture industry can be seen as expanding the enterprise boundaries of resource allocation and reducing the transaction costs of the digital culture industry. According to the property-rights theory of new institutional economics, network convergence in the digital culture industry can be seen as changing its property-rights structure. Effective design of property rights will improve resource allocation efficiency and industrial innovation. Neoinstitutional economics and new institution economics will be adapted in the research hypothesis and empirical study.

\section{B. Analytical Model of Network Industries Economics}

To study the effect of the different levels of network convergence on the digital culture industry, this paper divides network convergence into three groups, which are "no convergence of networks," "partial convergence of networks," and "full convergence of networks."

In the "no convergence of networks" condition, there is no business overlap between the internet, telephone networks, and television networks. Thus, consumers can only choose one network to consume the digital content products.

In the "partial convergence of networks," the consumers can partially choose other networks to consume the digital content products. However, the range and function of the choices are limited.

When networks are fully converged, network operators compete freely in the market. Thus, the consumers may consider different networks according to the price and services when they consume the digital content products.

a. No Convergence among the Networks

Suppose that there is number of consumers buy digital content products from enterprise A, and a consumer spends, part of the consumer's wages, to consume the digital content products. The networks and digital content products can be considered two complementary products in the economics of network industries. Only two types of products are used together; thus, the consumers can experience the consumer effect. In reality, the consumption of these products is complicated. For online games, e-books, and digital audio and video products, all types of networks require a subscription to specific channels, and digital content products require the use of pay-per-view services. However, there are some special conditions. For 
example, some digital cartoons may be sponsored by advertising companies, and the consumers only pay for the network service. As a simple model, people believe that the expenditure $w$ includes two separate parts. One part is to buy networks, and the other part is to purchase digital content products. Suppose that the consumer pays $p_{B}$ to access network B; as a consequence, the costs for the consumer for the digital content products is $e=w-p_{B}$.

Suppose that $\varphi$ is the fixed cost of the digital content enterprise. $p_{A}$ is the price of the digital content product. The number of digital content products can then be determined.

$$
S_{A}=\frac{\eta\left(w-p_{B}\right)}{\varphi}=\frac{\eta e}{\varphi}
$$

In this formula, $s_{A}$ is the number of digital content products, $\eta$ is the number of consumers, and $w$ is the consumer's wages to buy networks and digital content products. $p_{B}$ is the cost for the consumer to access network $\mathrm{B}$, and $e$ is the cost of the digital content products. $\varphi$ is the fixed cost of the digital content enterprise. This formula reveals the following proposition.

Proposition (1): The equilibrium number $s_{A}$ of the digital content products produced by the digital content, the enterprise is in direct proportion to the number $\eta$ of consumers and the total expense $e$. However, it is inversely proportional to the fixed cost $\varphi$ of digital content enterprises and the price $p_{B}$ for the network operators.

The utility function of the consumer can be expressed as

$$
U=\left\{\begin{array}{cc}
a s_{A}-p_{A} s_{A}-p_{B} & \text { purchasing network and DC product } \\
0 & \text { not purchasing }
\end{array}\right.
$$

In the formula above, $U$ is the utility function of the consumer, $a$ is the preference of the consumer, and $p_{A}$ is the price of the digital content product.

Assume that the digital content enterprises know the consumer's utility and thus set the price for the highest price that the consumer is willing to pay; the highest price is $p_{A}{ }^{m}=\frac{a s_{A}-p_{B}}{s_{A}}$ : The equilibrium number $s_{A}$ can be obtained.

$$
s_{A}=\frac{p_{B}}{a-p_{A}{ }^{m}}
$$


In the above formula, $p_{A}^{m}$ denotes the highest price of the digital content product, and the meaning of following $p_{B}^{m}$ is similar.

Formula (3) is plugged into equation (1), and the highest price can be obtained.

$$
p_{A}^{m}=a-\frac{p_{B} \phi}{\eta\left(w-p_{B}\right)}
$$

This equation reveals the following proposition:

Proposition (2): The price $p_{A}$ of the digital content, products are inversely proportional to the price $p_{B}$ of the network operators and the fixed cost $\varphi$ of the digital content enterprises, and it is in direct proportion to the consumer's preference $a$, expenditure $w$ and the number $\eta$ of consumers.

Formula (4) is plugged into formula (1), and the equilibrium number $S_{A}$ can be obtained.

$$
s_{A}=\frac{w \eta}{a \eta+\phi-p_{A}{ }^{m} \eta}
$$

This formula reveals the following proposition:

Proposition (3): The equilibrium number $S_{A}$ of the digital content, products are in direct proportion to the consumer's expenditure $W$, the number $\eta$ of consumers and the price $p_{A}$ of digital content products. It is inversely proportional to the consumer's preference $a$ and the fixed costs $\varphi$ of the digital content enterprises.

The fixed costs $\varphi$ of the digital content enterprises can be obtained through equation (4).

$$
\phi=\frac{\eta w\left(a-p_{A}^{m}\right)}{p_{B}}-\eta\left(a-p_{A}^{m}\right)
$$

This formula can reveal proposition (4):

Proposition (4): The fixed cost $\varphi$ of digital content enterprises is inversely proportional to the price $p_{B}$ of the network operators.

Propositions (1), (2), (3), and (4) can be summarized as follows: the price $p_{A}$ of the digital content, the product is in direct proportion to the price $p_{B}$ of the network operators, and it is inversely proportional to the fixed costs $\varphi$ of the digital content enterprises. It directly relates to the consumer's preference $a$, expenditure $w$ and the number $\eta$ of 
consumers.

The equilibrium number $S_{A}$ of digital content, products are in direct proportion to the number $\eta$ of consumers, the expenditure $w$ of consumers, the total expenses $e$ of the consumer and the price $p_{A}$ of digital content products. It is inversely proportional to the fixed costs $\varphi$ of digital content enterprises, the consumer's preference $a$ and the price $p_{B}$ of the network operators.

To summarize, the higher price of the network and the higher fixed costs of the digital content enterprises are unfavorable to the development of the digital culture industry. However, a more significant number of consumers and the higher expenses paid by the consumers can promote the development of the digital culture industry.

b. Partial Interconnection among Three Networks

Assume that digital content enterprise A, network operators B, and network operators $C$ are in the same market. Furthermore, there is a difference between the $\mathrm{B}$ network and the $\mathrm{C}$ network; that is to say, network C can only provide part of network B's service.

Because a similar network service is provided, network operator $\mathrm{C}$ is the competitor of network operator B. Assume that network B is dominant. Network $C$ is in a lower position. From this point of view, the competition between network operators B and C forms a Stackelberg model. The result of this model is that the service provided by network operator $\mathrm{C}$ is half of that of network operator B. We assume that the prices of the service supplied by two network operators are equal. Meanwhile, the cost of the service provided by the two network operators is $p_{B C}$, which is different from the price $p_{B}$. Thus, the utility function of the consumer is as follows:

$U_{1}$

$=\left\{\begin{array}{cc}\frac{2}{3} a s_{A}-\frac{2}{3} p_{A} s_{A}+\frac{1}{3} a s_{A}-\frac{1}{3} p_{A} s_{A}-p_{B C} & \text { purchasing two kinds of networks and DC product } \\ 0 & \text { not purchasing }\end{array}\right.$

That is,

$U_{1}=\left\{\begin{array}{ccc}a s_{A}-p_{A} s_{A}-p_{B C} & \text { purchasing two kinds of networks and DC product } \\ 0 & \text { not purchasing }\end{array}\right.$

In this utility function of the consumer, because the result of the competition between two network operators, $\mathrm{B}$, and $\mathrm{C}$, the service of network operator $\mathrm{B}$ is $2 / 3$ of the market, and the benefit of network operator $\mathrm{C}$ 
accounts for $1 / 3$ of the market. We can assume that the number $\frac{2}{3} s_{A}$ of digital content, products are from the service of operator $\mathrm{B}$ and $\frac{1}{3} s_{A}{ }^{3}$ comes from the service of operator $\mathrm{C}$ when the consumer buys the number $s_{A}$ of digital content products. The consumer pays for a network service at the same time; that is, the price of the network service is $p_{B C}$.

We assume that the market-clearing price of the network operator is $P=b-Q(q)$. Therefore, the former price of network operator $\mathrm{B}$ is $p_{B}=b-q_{B}$, and $q_{B}$ is the number of network services. Therefore,

$$
q_{B}=b-p_{B}
$$

The market-clearing price of network operators $\mathrm{B}$ and $\mathrm{C}$ is as follows.

$$
p_{B C}=b-q_{B}-q_{C}=b-q_{B}-\frac{1}{2} q_{B}=b-\frac{3}{2} q_{B}
$$

Formula (8) is plugged into formula (9).

$$
p_{B C}=\frac{3}{2} p_{B}-\frac{1}{2} b
$$

Because the number and pride of the network service must be greater than $0, b<p_{B}$ can be obtained with formula (7). Similarly, $p_{B C}=\frac{3}{2} p_{B}-\frac{1}{2} b=p_{B}+\frac{1}{2}\left(p_{B}-b\right)<p_{B}-$ that is to say,

$$
p_{B C}<p_{B}
$$

Formula (10) is plugged into formula (7), $U_{1}=\left\{\begin{array}{cc}a s_{A}-p_{A} s_{A}-\left(\frac{3}{2} p_{B}-\frac{1}{2} b\right) & \text { purchasing two kinds of networks and DC product } \\ 0 & \text { not purchasing }\end{array}\right.$

The following result can be obtained by comparing two utility functions, (2) and (12).

$$
U_{1}>U
$$

We then obtain proposition (5):

Proposition (5): Consumers can obtain more services under the partial convergence of networks condition than under the condition of no convergence of networks.

In this case, the number of products provided by the digital content enterprises is as follows. 


$$
S_{A 1}=\frac{\eta\left[w-\left(\frac{3}{2} p_{B}-\frac{1}{2} b\right)\right]}{\varphi}
$$

Comparing (14) and formula (1), $s_{A 1}>s_{A}$ can be obtained.

Thus, proposition (6) is as follows:

Proposition (6): Consumers are willing to buy more digital content products under the partial network convergence condition than under the condition of no convergence of networks.

Similarly, if the price of digital content products is the maximum price consumers are willing to pay, the following formula (15) can be obtained.

$$
S_{A 1}=\frac{\frac{3}{2} p_{B}-\frac{1}{2} b}{a-p_{A 1} m}
$$

Equation (15) is plugged into equation (14).

$$
p_{A 1}^{m}=a-\frac{\phi\left(\frac{3}{2} p_{B}-\frac{1}{2} b\right)}{\eta\left[w-\left(\frac{3}{2} p_{B}-\frac{1}{2} b\right)\right]}
$$

Compare the price of the digital content product under the no network convergence and partial network convergence conditions; that is to say, compare formula (16) and formula (4); $p_{A 1}^{m}<p_{A}^{m}$ । Can be obtained. Thus, we have proposition (7):

Proposition (7): The price of digital content products is reduced from the no network convergence condition to the partial convergence condition.

The fixed cost $\phi_{1}$ of the digital content, the enterprise can be obtained by formula (16).

$$
\phi_{1}=\frac{\eta w\left(a-p_{A 1}{ }^{m}\right)}{\frac{3}{2} p_{B}-\frac{1}{2} b}-\eta\left(a-p_{A 1}{ }^{m}\right)
$$

Compare the fixed cost under the no network convergence and partial network convergence; that is to say, compare formula (17) and formula (6); $\phi_{1}>\phi$ is obtained. The result reveals the following proposition:

Proposition (8): The fixed costs of the digital content enterprises increase from the no network convergence condition to the part network convergence condition. 
The proposition shows that partial network convergence can encourage the enterprise to increase fixed costs for $R \& D$ and the innovation of digital products.

To summarize the above analysis, some results can be obtained. From no network convergence to partial network convergence, the service price of the network operators and the cost of the digital content products all decline. The number of digital content products that the consumer is willing to buy and consumer utility all increase. Meanwhile, digital content enterprises are also ready to increase fixed costs for $R \& D$ and product innovation. In short, a partial network convergence can promote the development of the digital culture industry.

c. Complete Network Convergence

When the networks make complete interconnections, network operators B and C can freely match digital content enterprise A. Hence, the competitive position between $\mathrm{B}$ and $\mathrm{C}$ is equal. Thus, we can project that the competitive result between $\mathrm{B}$ and $\mathrm{C}$ is that the price of the two networks services is similar, and the number of the two network services is also equal; that is to say, $p_{B}=p_{C}$ and $q_{B}=q_{C}$.

Based on the Cournot model, the market-clearing price Of the network, service is as follows under the complete network convergence condition.

$$
p_{B B}=b-q_{B}-q_{C}=b-2 q_{B}
$$

Formula (8) is plugged into formula (18). Thus, formula (19) can be obtained.

$$
p_{B B}=2 p_{B}-b
$$

The consumer's utility function is as follows under the complete network convergence condition:

$$
U_{2}=\left\{\begin{array}{cc}
a s_{A}-p_{A} s_{A}-\left(2 p_{B}-b\right) & \text { purchasing two kinds of networks and DC product } \\
0 & \text { no purchasing }
\end{array}\right.
$$

Similarly, can be obtained. Proposition (9) is as follows:

Proposition (9): Higher levels of network convergence denote more excellent utility for the consumer.

Under these circumstances, the number $S_{A 2}$ of digital content products provided by the enterprises can be found. 


$$
S_{A 2}=\frac{\eta\left[w-\left(2 p_{B}-b\right)\right]}{\varphi}
$$

When comparing the number of products provided by digital content enterprises under the no network convergence, partial convergence, and complete convergence conditions, we find that $s_{A 2}>s_{A 1}>s_{A}$. Thus, proposition (10) is as follows.

Proposition (10): Higher levels of network convergence denote a higher number of digital content products provided by enterprises.

Similarly, the highest price for digital content products that consumers are willing to pay can be obtained.

$$
p_{A 2}^{m}=a-\frac{\phi\left(2 p_{B}-b\right)}{\eta\left[w-\left(2 p_{B}-b\right)\right]}
$$

Similarly, we can find $p_{A 2}<p_{A 1}<p_{A}$, so proposition (11) is as follows:

Proposition (11): Higher levels of network convergence denote lower prices of digital content products.

In formula (22), we obtain

$$
\phi_{2}=\frac{\eta w\left(a-p_{A 2}{ }^{m}\right)}{2 p_{B}-b}-\eta\left(a-p_{A 2}{ }^{m}\right)
$$

Similarly, $\phi_{A 2}>\phi_{A 1}>\phi_{A}$ Is obtained. Proposition (12) is as follows:

Proposition (12): When the levels of network convergence are higher, digital content enterprises are willing to invest higher fixed costs to modernize their digital content products.

In summary, with the higher levels of network convergence, the service price of the network operators and the product price of the digital content enterprises all decline, and the digital content enterprises are willing to provide more products. The number of digital content products that consumers are eager to buy and their utility all increase. Digital content enterprises and social capital are also willing to invest more money to improve the quality of their digital content products or develop new products. 


\section{Application of the theory of network convergence and the hypotheses}

The institution is a widespread habit of thinking in neo-institutional economics, while routine is lagging and technology is forward. In reality, the development of network convergence is also the same. In many countries' practice of network convergence, technology development was the first, but the regulatory policy was gradually liberalized. Therefore, the result of network convergence is based on the development of technology and the subsequent deregulation.

According to neo-institutional economics, the optimal resource allocation may improve industrial or public efficiency through policy adjustment and government intervention (Khalil, 1993). For the digital culture industry, the essence of network convergence is to change the infrastructure of the digital culture industry. To respond to this change, the role of the market may be incomplete, and the government needs to make relevant policies to make up for it. China, for example, announced network convergence, followed by several policies related to the digital culture industry (Gao, 2013). Therefore, hypothesis 1 is proposed.

H1: Network convergence has promoted the policy formulation related to the digital culture industry. That is, network convergence has policy effects.

In the above model of network industries economics, we have drawn that network convergence will bring more social capital for the digital culture industry. In addition, according to new institutional economics (Nabli and Nugent, 2006), network convergence will affect resource allocation structure. In the input elements of the digital culture industry, capital has higher liquidity and faster response speed, and talent and technology, and other factors often rely on the development of money (Cao, 2015). The network convergence and the policy adjustment of the digital culture industry have allowed the capital to get a higher rate of return. At the same time, the flow to the sectors with higher returns is also a manifestation of the improvement in the efficiency of capital allocation (Wurgler, 2000). In 2012, for example, some publishing groups in China set up digital media companies or digital publishing departments after the pilot policy of tri-network convergence and the government's approach to vigorously develop the digital culture industry (Tu, 2012). Thus, hypothesis 2 and 3 is proposed. 
H2: The network convergence promotes the capital to flow to the digital culture industry. That is, the network convergence has the capital effect.

H3: The policy effect of network convergence also has a positive impact on the capital.

Based on a proposition (11), Hypothesis 4 is raised.

$\mathrm{H} 4$ : The network convergence may reduce the operation cost of digital content enterprises.

In the above model of network industries economics, we have drawn that network convergence is beneficial to decreasing the communication industry's price. This price is a part of the cost of the digital culture industry. The theory of new institutional economics lies in the transaction cost. Various forms of the institution result from the efforts to save the transaction cost (Nabli and Nugent, 2006). Network convergence and the policy adjustment of the digital culture industry reduce the transaction cost of the digital culture industry. The exact impact of capital will also change the ownership of digital content companies, affecting the change in transaction costs. Therefore, hypotheses 5 and 6 are proposed.

H5: The policy effect of network convergence may significantly reduce the operating costs of the digital culture industry.

H6: The capital effect of network convergence may significantly reduce the operating costs of the digital culture industry.

The theory of institutional innovation is a branch of new institutional economics. The development of new technology must establish a systematic property-right institution to raise the private rate of return of creation and make it close to social income. From this theory, the policy effect is helpful to promote the innovation of the digital culture industry. Social capital is a crucial factor in determining the success of technical cooperation and technological innovation. It is also a basic form of resource allocation (Cao, 2015). Therefore, we can think that the capital effect is beneficial to the innovation of the digital culture industry. Previous studies support this view as well. For example, Yang (2011) proposed that the digital publishing industry is an "adhesive" high-tech industry. At present, the development of the digital publishing industry belongs to the "input" mode of driving growth, and venture capital has the attribute of technology suppliers to the scale growth of the digital publishing industry. Because it is challenging to obtain digital content industrial innovation data, this paper does not test the impact of policy effect and capital effect on industrial 
innovation. This paper only puts forward the following hypotheses.

In the above model of network industries economics, we have drawn that cost reduction of the digital culture industry may improve firm performance. So hypothesis 7 is proposed.

H7: The reduction of the operation cost of the digital culture industry may improve the performance of the sector.

In addition to the above seven hypotheses proposed by the previous relevant research. Firstly, in the above hypotheses, the only operating cost directly affects the firm performance. In industrial organization theory, adjustment of industrial policy and the capital market could improve the strong performance. Then whether does policy effect, and capital effect have a significant direct impact on the firm performance? Secondly, whether a series of middle variables from Network convergence to Firm performance significantly affects the implications? The questions are as follows.

Q1: Whether the Policy effect has a significant direct impact on the firm performance of digital content industries.

Q2: Does the Capital effect have a significant direct impact on the firm performance of digital content industries.

Q3: Whether Policy effect, Capital effect, and Operating cost significantly mediate network convergence and Firm performance. And whether does Policy effect and Capital effect have a significant mediating impact between network convergence and Operating cost.

Based on the above analysis, this paper proposes the theoretical framework of the effect mechanism of network convergence on the digital culture industry, as shown in figure 1 .

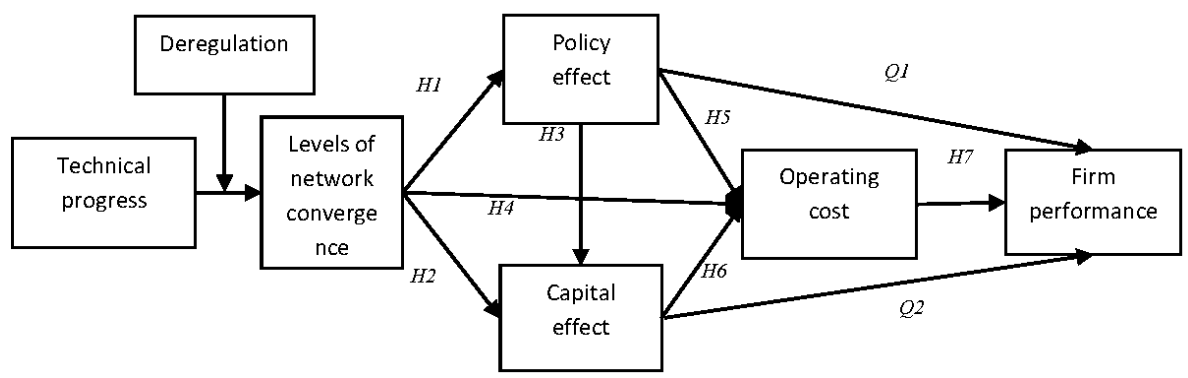

Figure 1. The theoretical framework of effect mechanism of networks convergence on the digital culture industry 


\section{METHODS}

\section{a. Sample and Data Collection}

This paper takes China as the object of empirical study. The relevant departments of the Chinese government have long recognized the importance of network convergence. On Mar15 ${ }^{\text {th }}$, 2001, tri-network convergence was presented in the Chinese tenth five-year plan. However, it did not enter a substantial development stage. Chinese ex-premier Wen Jiabao chaired a State Council executive meeting on January 13, 2010, decided to accelerate the convergence process between telecommunication networks, broadcast networks, and the internet, and set a five-year goal to promote tri-network convergence with a pilot and promotion substantially. On June 30, 2010, the Chinese State Council identified 12 pilot cities for the tri-network convergence. On January 15, 2012, it identified 42 cities as the second pilot area. Tri-network convergence in China has made a specific breakthrough for business. In particular, many new companies are appearing; such as Internet Protocol Television, Interactive T.V., and Mobile T.V. However, full tri-network convergence has not been realized in China. In addition, its market and operations systems are not sufficiently mature. Thus, full network convergence must wait several years for network construction (Rong, 2014).

The empirical study chose listed firms in China as a sample for two reasons: these listed firms have a specific scale and representation in digital content industries. Some authoritative databases can easily collect the most comparable data of the listed firms with high reliability. The selection criterion for the firms is that their main business must belong to the digital culture industry and must be listed firms. Thus, 31 listed firms in China meet these criteria. The collected data come from the Chinese CSMAR database. GTA Information Technology Co., Ltd. developed a CSMAR database according to the international database criteria of CRSP and COMPUSTAT. This research database is specifically aimed at China's economic and financial fields. It includes 11 series, including economic studies, industry studies, company studies, stock markets, fund markets, bond markets, derivative markets, overseas markets, and special assignments. The CSMAR database is used in China and accepted as a Wharton study service system by the Wharton School in the U.S. and is used by famous universities, such as Princeton University and the University of Chicago. The database can satisfy the needs of many researchers and is an essential tool of empirical study. 
This paper used panel data to conduct an empirical study. The data in this paper were quarterly. The time range was from the first quarter of 2009 to the third quarter of 2013 for 19 quarters. The three data types in econometrics are time series data, cross-sectional data, and panel data. Time series data can show multiple periods and reflect the trends of the study objects; however, they can only study one sample. The cross-sectional data can look at various variables; however, they can only observe a one-time period. By contrast, panel data can keep multiple models and periods. Panel data, also called longitudinal data or cross-sectional time-series data, are data where numerous cases were observed at two or more periods (Stock et al., 2003). The digital culture industry is an emerging industry, and the development time of tri-network convergence is shorter in China. Therefore, time-series data are not appropriate.

Furthermore, there are only 31 firms that meet the above criteria. Thus, cross-sectional data are not ideal. In summary, panel data are more suitable.

\section{b. Variables and Measurement}

An econometric model is used in testing H1-H7 and Q1-Q3. To test these research hypotheses and questions, the related variables need to be proposed.

Tobin's $Q$ has often applied abroad in studying firm performance (Bardhan et al., 2013). However, many Chinese scholars often use the Rate of Return on Common Stockholders' Equity (abbreviated as ROE) to study firm performance based on China's national conditions. Thus, this paper also uses ROE to represent strong performance. Meanwhile, the report uses the Operation Expense Rate as the operating expense index of digital content enterprises. The Operation Expense Rate is the proportion of Operating expenses and revenues. Because the CSMAR database does not have data on corporate capital injections, this paper replaces it with another related indicator: corporate financial leverage. If there is a large amount of low-cost capital available for firms to choose from, its use of high-cost-based economic power, such as loans, will become smaller. After controlling the debt variables, the supply level of industrial capital is negatively related to financial leverage. The lower the economic power, the higher the supply level of industrial capital. In addition to these indicators, listed companies' assets and liabilities are also available in the Chinese CSMAR database.

Among all variables, the Chinese CSMAR database cannot provide the values of network convergence level and the development policy of the digital culture industry. Government regulation is the most significant influencing 
factor to the development of the tri-network convergence of China. The historical separation between telecommunications and television and the strict regulation has resulted in an asymmetric market in which phone companies control the conduit and broadcasters dominate the content (Liu, 2013). The adoption and implementation of government policies play a vital role in promoting tri-network convergence in China (Mi, 2015). Every pilot scheme can be considered as a milestone of the progress of tri-network convergence. Thus, this paper believes that network convergence in the second pilot stage is more significant than in the first pilot stage. Tri-network intersection in China was not allowed before July 2010. Thus, in this study, the value of the tri-network convergence variable was set at 0 before July 2010. Twelve cities served as the first pilot group to provide two-way broadcasting and telecommunication service after July 2010. The 48 towns became the second pilot group in January 2012. However, the pilot tasks in 2012 were different from the pilot tasks in 2010. The pilot reform in 2012 resulted in a significant breakthrough. China Telecom, China Unicom, and China Mobile all obtained a "Permit of Information Network AudioVisual Program" and "Permit of Radio/ T.V. Program Production" issued by the State Administration of Radio Film and Television. China Telecom and China Unicom operated network audio-visual programs, mobile television distribution, and IPTV transmission services.

In contrast, China Mobile was permitted to operate the first two services only. If the value of the tri-network convergence variable was one from July 2010 to December 2011, its value could be considered to be two after January 2012. The buy two only represents higher convergence levels of tri-network. It cannot describe the full tri-network convergence according to the current status of trinetwork convergence in China.

Concerning policy effect, this paper measures the cumulative number of policies to promote the development of the digital culture industry formulated by the relevant national or local government departments under integrating the three networks. The measurement of variables is presented in Table 1.

Table 1. Variables and measurement

\begin{tabular}{|c|c|}
\hline Dependent variables & Measurement \\
\hline Firm performance & $\begin{array}{l}\text { It can be represented by ROE (the abbreviation of } \\
\text { "Rate of Return on Common Stockholders' Equity). } \\
\text { And } \mathrm{ROE} \text { is computed by dividing the net income } \\
\text { by the shareholder's equity. It measures the success } \\
\text { of a digital content company in generating revenue } \\
\text { for the benefit of common stockholders. }\end{array}$ \\
\hline
\end{tabular}




\begin{tabular}{|c|c|}
\hline Dependent variables & Measurement \\
\hline $\begin{array}{l}\text { Independent variable } \\
\text { and mediator variables }\end{array}$ & Measurement \\
\hline Network convergence & $\begin{array}{l}\text { It has been explained in the body text. } \\
\text { The value of network convergence is } 0 \text { before the } \\
\text { policy of the first pilot group is issued. The value of } \\
\text { network convergence is one after the procedure of } \\
\text { the first pilot group is issued and before the policy } \\
\text { of the second pilot group is issued. And the value of } \\
\text { network convergence is two after the policy of the } \\
\text { second pilot group is given. }\end{array}$ \\
\hline Policy effect & $\begin{array}{l}\text { It is the digital culture industry policy that relative } \\
\text { government departments issue in response to } \\
\text { network convergence. } \\
\text { This paper uses a cumulative quantity of policy } \\
\text { to measure policy. Because the first stage of the } \\
\text { procedure is still practical after the second stage of } \\
\text { policy is issued. }\end{array}$ \\
\hline Capital effect & $\begin{array}{l}\text { Financial leverage uses debt to increase the expected } \\
\text { return on equity, and it is measured by the ratio } \\
\text { of debt to debt plus equity. Although a company with } \\
\text { financial leverage that is too high will risk bankruptcy, } \\
\text { this is not always negative; a certain level of economic } \\
\text { power can increase the shareholders' return on } \\
\text { investment. }\end{array}$ \\
\hline Operating cost & $\begin{array}{l}\text { Operation Expense Rate can represent it. Operation } \\
\text { Expense Rate is the proportion of Operating expense } \\
\text { and revenues. }\end{array}$ \\
\hline Control variables & Measure \\
\hline Assets & $\begin{array}{l}\text { Total assets are the sum of all cash, } \\
\text { investments, furniture, fixtures, equipment, } \\
\text { receivables, intangibles, and any other valuable } \\
\text { items owned by the digital content company. }\end{array}$ \\
\hline
\end{tabular}




\begin{tabular}{ll}
\hline Dependent variables & Measurement \\
\hline Liability & $\begin{array}{l}\text { Liability refers to the enterprise from past transactions } \\
\text { or events expected, which will lead to the outflow } \\
\text { of economic benefits from the enterprise's current } \\
\text { obligations. }\end{array}$ \\
\hline
\end{tabular}

\section{c. Descriptive Statistics}

The summary descriptive statistics of the sample are as follows (see Table 2). When the level of network convergence increases from 0 to 2 , the mean values of assets and policy effect continuously improve, and the mean values of operating cost and capital effect constantly decrease. In contrast, the mean values of firm performance were unstable. With the gradual deepening of network convergence, the mean values of strong performance increased and then decreased. Whether the development trend of these variables is caused by network convergence can be tested by empirical study.

Table 2. Descriptive statistics

\begin{tabular}{|c|c|c|c|c|c|c|}
\hline & $\begin{array}{l}\text { Network } \\
\text { convergence }\end{array}$ & $\mathrm{N}$ & Minimum & Maximum & Mean & $\begin{array}{l}\text { Std. } \\
\text { Deviation }\end{array}$ \\
\hline \multirow{4}{*}{$\begin{array}{l}\text { Firm } \\
\text { performance }\end{array}$} & $0-2$ & 453 & -0.86 & 1.58 & 0.04 & 0.12 \\
\hline & 2 & 204 & -0.86 & 0.15 & 0.04 & 0.07 \\
\hline & 1 & 138 & -0.59 & 1.58 & 0.07 & 0.19 \\
\hline & 0 & 111 & -0.42 & 0.31 & 0.01 & 0.09 \\
\hline \multirow{4}{*}{$\begin{array}{l}\text { Operating } \\
\text { cost }\end{array}$} & $0-2$ & 498 & 0.32 & 1.78 & 0.70 & 0.17 \\
\hline & 2 & 216 & 0.32 & 1.78 & 0.66 & 0.17 \\
\hline & 1 & 157 & 0.33 & 1.02 & 0.70 & 0.15 \\
\hline & 0 & 125 & 0.38 & 1.57 & 0.76 & 0.17 \\
\hline \multirow{4}{*}{ Capital effect } & $0-2$ & 503 & 0.02 & 3.04 & 0.43 & 0.43 \\
\hline & 2 & 216 & 0.04 & 1.89 & 0.36 & 0.26 \\
\hline & 1 & 162 & 0.02 & 3.04 & 0.42 & 0.43 \\
\hline & 0 & 125 & 0.04 & 2.67 & 0.57 & 0.61 \\
\hline
\end{tabular}




\begin{tabular}{|c|c|c|c|c|c|c|}
\hline & $\begin{array}{l}\text { Network } \\
\text { convergence }\end{array}$ & $\mathrm{N}$ & Minimum & Maximum & Mean & $\begin{array}{l}\text { Std. } \\
\text { Deviation }\end{array}$ \\
\hline \multirow{4}{*}{ Policy effect } & $0-2$ & 500 & 0.0 & 26.0 & 10.17 & 9.42 \\
\hline & 2 & 216 & 14.0 & 26.0 & 19.88 & 4.98 \\
\hline & 1 & 1.0 & 10.0 & 5.01 & 2.94 & 1.0 \\
\hline & 0 & 126 & 0.0 & 0.0 & 0.00 & 0.00 \\
\hline \multirow{4}{*}{$\begin{array}{l}\text { Network } \\
\text { Convergence }\end{array}$} & $0-2$ & 506 & 0 & 2 & 1.18 & 0.81 \\
\hline & 2 & 216 & 2 & 2 & 2 & 0 \\
\hline & 1 & 163 & 1 & 1 & 1 & 0 \\
\hline & 0 & 127 & 0 & 0 & 0 & 0 \\
\hline \multirow{4}{*}{ Ln(Assets) } & $0-2$ & 503 & 13.08 & 23.39 & 21.51 & 1.21 \\
\hline & 2 & 216 & 17.92 & 23.39 & 21.81 & 1.01 \\
\hline & 1 & 162 & 13.08 & 23.30 & 21.30 & 1.46 \\
\hline & 0 & 125 & 18.39 & 23.18 & 21.27 & 1.06 \\
\hline \multirow{4}{*}{ Ln(Liability) } & $0-2$ & 503 & 11.51 & 22.93 & 20.37 & 1.34 \\
\hline & 2 & 216 & 17.92 & 22.93 & 20.57 & 1.22 \\
\hline & 1 & 162 & 11.51 & 22.76 & 20.13 & 1.61 \\
\hline & 0 & 125 & 17.51 & 22.63 & 20.33 & 1.09 \\
\hline
\end{tabular}

\section{RESULTS AND DISCUSSION}

\section{a. Result}

The panel data can be analyzed by a fixed-effect model and random effect model in Econometrics. The question as to which model is more suitable for the panel data of this paper can be answered by the econometrics test. Software Stata 12.0 is applied in test $\mathrm{H1}-\mathrm{H} 7$, which estimates econometric models.

In model 1 , the main body of Policy effect is the government. The government pays more attention to the scale and influence of the digital culture industry, so the firm's assets can be an independent variable. The main body of the Capital effect is the capital market. The debt ratio is an essential factor of the market investment so that the liability can be an independent variable. In addition, because the numerical values of assets and liability are tremendous, adding a natural logarithm to assets and liability in regression. The result is shown in Table 3. 
Informasi, Vol. 51. No. 2. (2021), 195-226

Table 3. Fixed and random effects estimation results of empirical study

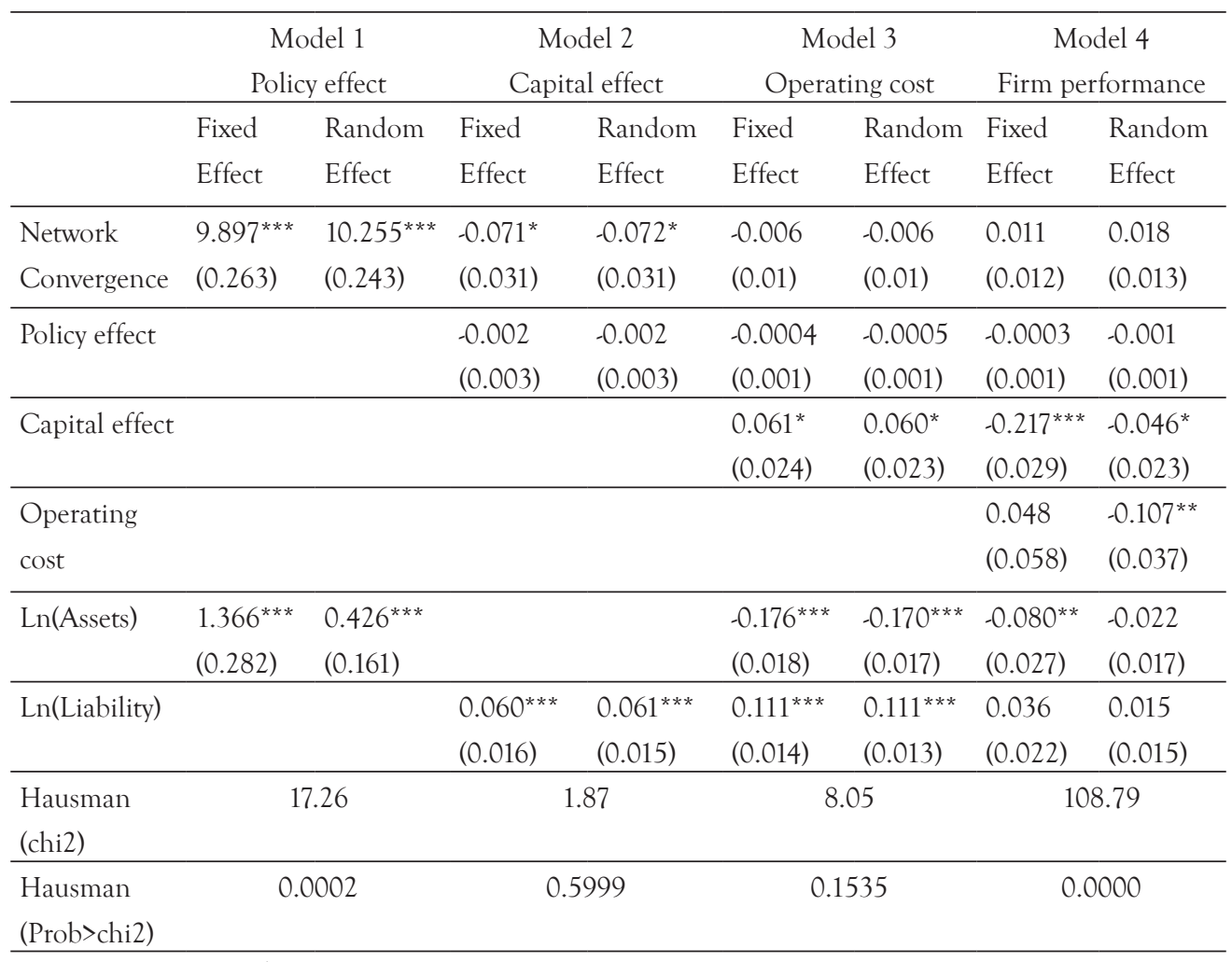

Note: ${ }^{*} p<0.05 ;{ }^{* *} p<0.01 ;{ }^{* * *} p<0.001$.

The Hausman test is first performed before the hypothesis test. In the "Policy effect" model as a dependent variable, chi $2=17.26$ and Prob $>$ chi $2=0.0002$ of Hausman; thus, a random effect model cannot be rejected and is more appropriate as an estimation model. In the random effect estimation model of "Policy effect," the regression coefficient of the "Network convergence" variable is positive; moreover, it is statistically significant at the level of $1 \%$. Hypothesis 1 is supported.

In the "Capital effect" model as a dependent variable, chi2 $=1.87$ and Prob>chi2 $=0.5999$ of Hausman, a fixed-effect model is more appropriate as an estimation model. In the fixed effect estimation model of "Capital effect," the regression coefficient of the "Network convergence" variable is statistically significant. However, it is harmful and contrary to Hypothesis 2. In addition, the effect of the "Policy effect" on the "Capital effect" is not statistically significant. 
Therefore, hypothesis 3 is not supported.

In the "Operating cost" model as a dependent variable, chi2 $=8.05$ and Prob>chi $2=0.1535$ of Hausman, a fixed-effect model is more appropriate as an estimation model. In the fixed effect estimation model of "Operating cost," the regression coefficients of "Network convergence" and "Policy effect" aren't statistically significant. Therefore, Hypothesis 4 and Hypothesis 5 aren't supported. There is a significant positive effect between "Capital effect" and "Operating cost." The result is opposite to Hypothesis 6.

In the "Firm performance" model as a dependent variable, chi2 $=108.79$, and Prob $>$ chi $2=0.0000$ of Hausman, a random effect model is more appropriate as an estimation model. In the random effect estimation model of "Firm performance," the regression coefficient of the variable "Operating cost" is -0.107. Moreover, it is statistically significant. Hypothesis 7 is supported. The "Policy effect" regression coefficient isn't statistically significant, and the regression coefficient of "Capital effect" is -0.046 . Moreover, it is statistically significant.

The paper uses the process plugin of SPSS to study of mediator effect of the variables. The result is Table. 4. Because the signs of BootLLCI and BootUlCI of all Paths are different, all indirect effects are not significant. The indirect effects of Network Convergence on Operating cost in Table 5. Only the indirect effect of "Policy effect $\rightarrow$ Capital effect" as mediator variables is significant in all paths.

Table. 4 Indirect effects of Network Convergence on Firm performance

\begin{tabular}{|c|c|c|c|c|}
\hline Paths of indirect effects & Effect & BootSE & BootLLCI & BootUlCI \\
\hline $\begin{array}{l}\text { Path 1: Network converge } \rightarrow \text { Policy } \\
\text { effect } \rightarrow \text { firm performance }\end{array}$ & -.0152 & .0110 & -.0378 & .0054 \\
\hline $\begin{array}{l}\text { Path 2: network converge } \rightarrow \text { capital } \\
\text { effect } \rightarrow \text { firm performance }\end{array}$ & .0081 & .0081 & .0070 & .0256 \\
\hline $\begin{array}{l}\text { Path 3: network converge } \rightarrow \text { Operating } \\
\text { cost } \rightarrow \text { firm performance }\end{array}$ & .0003 & .0015 & -.0040 & .0025 \\
\hline $\begin{array}{l}\text { Path 4: network converge } \rightarrow \text { Policy } \\
\text { effect } \rightarrow \text { capital effect } \rightarrow \text { firm performance }\end{array}$ & .0020 & .0042 & -.0110 & .0069 \\
\hline $\begin{array}{l}\text { Path } 5 \text { : network converge } \rightarrow \text { Policy } \\
\text { effect } \rightarrow \text { Operating cost } \rightarrow \text { firm performance }\end{array}$ & .0000 & .0010 & -.0017 & .0025 \\
\hline $\begin{array}{l}\text { Path } 6: \text { network converge } \rightarrow \text { capital } \\
\text { effect } \rightarrow \text { Operating cost } \rightarrow \text { firm performance }\end{array}$ & .0010 & .0039 & -.0087 & .0077 \\
\hline
\end{tabular}




\begin{tabular}{lclll}
\hline Paths of indirect effects & Effect & BootSE & BootLLCI & BootUlCI \\
\hline Path $7:$ network converge $\rightarrow$ Policy & .0003 & .0016 & -.0039 & .0035 \\
effect $\rightarrow$ capital effect $\rightarrow$ Operating & & & & \\
cost $\rightarrow$ firm performance & & & & \\
Total & -.0101 & .0119 & -.0340 & .0125 \\
\hline
\end{tabular}

Table. 5 Indirect effects of Network Convergence on Operating cost

\begin{tabular}{llllll}
\hline Paths of indirect effects & & Effect & BootSE & BootLLCI & BootUlCI \\
\hline $\begin{array}{l}\text { Path 8: Network } \\
\text { effect } \rightarrow \text { Operating cost }\end{array}$ & converge $\rightarrow$ Policy & 0.044 & 0.043 & -0.041 & 0.128 \\
$\begin{array}{l}\text { Path 9: Network converge } \rightarrow \text { Policy effect } \rightarrow \\
\text { Capital effect } \rightarrow \text { Operating cost }\end{array}$ & -0.177 & 0.08 & -0.328 & -0.015 \\
$\begin{array}{l}\text { Path 10: Network converge } \rightarrow \text { Capital } \\
\text { effect } \rightarrow \text { Operating cost }\end{array}$ & & & & \\
Total effect & -0.064 & 0.063 & -0.066 & 0.186 \\
\hline
\end{tabular}

This paper summarizes the effect mechanism of network convergence in China on the digital culture industry based on the above results, as shown in figure 2 below.

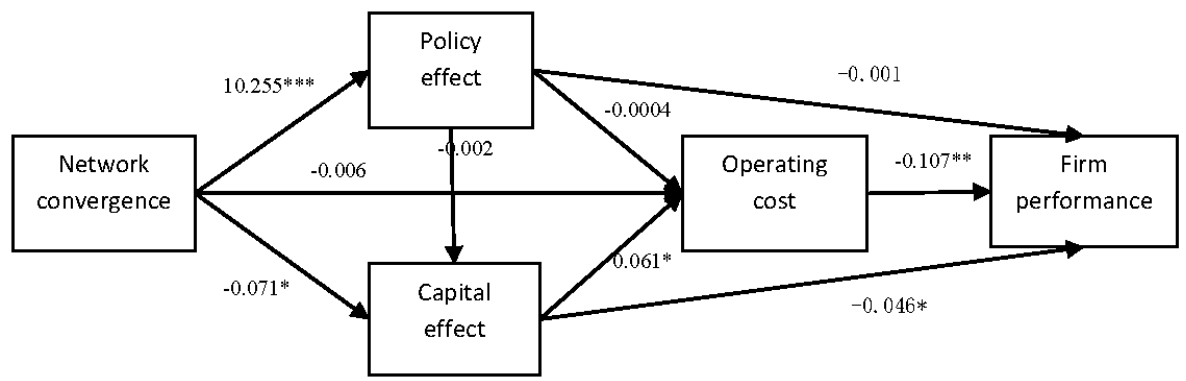

Figure 2. Test result on effect mechanism of network convergence on the digital culture industry in China

\section{b. Discussion}

This paper applied network industry economics and institutional economics to study the effect mechanism of network convergence on the digital culture industry. For the development of the digital culture industry, network convergence is an external technological or institutional breakthrough. The 
effect of network convergence on the digital culture industry is complicated. However, many previous studies neglected the complex relation between network convergence and the digital culture industry. This paper introduced policy, capital, and operating cost factors to explain the complicated connection. In theory, network convergence is significantly related to the development policy of the digital culture industry and the capital investment of the digital culture industry. That is, the network convergence can produce significant policy effects and capital effects.

Meanwhile, the policy effect and capital effect of network convergence have a negative relationship with the operating costs of the digital culture industry. That is, they will reduce the operational costs of digital content firms. Finally, there is a negative correlation between the operating costs of digital content firms and their performance. That is, the cost reduction of digital content firms can improve their performance.

The empirical study does not support the partial theoretical views. The development of network convergence has promoted relevant government departments to develop many development policies for the digital culture industry. However, the empirical results showed that policy effect has no significant negative relationship with the operating cost of the digital culture industry, and it has no meaningful positive relationship with firm performance. Therefore, it can be considered that the policy effect does not directly reduce the cost of the digital culture industry and increase its performance.

The development of network convergence may cause more capital to flow into the digital culture industry in theory. However, statistics showed that investment in the digital culture industry decreased in China's network convergence. The empirical results also showed that network convergence has a significant negative effect on capital effect. This conclusion is also inconsistent with hypothesis 2 . The reason may be related to the economic situation at the time. Under the background of the continued impact of the 2008 financial crisis, the capital side was more cautious in the investment of the digital culture industry. The empirical results also showed that the capital effect has a significant positive impact on the operating cost of the digital culture industry. That is, the capital effect increases the operating cost of the digital culture industry. The possible reason is that most of the capital is primarily short-term investments, which causes rising transaction costs.

On the other hand, the policy effect has no significant impact on capital effects, which shows that the market is not very optimistic about the impact 
of network convergence on the digital culture industry. That is, the return on investment is not high. Empirical research has also concluded that the capital effect has a significant negative impact on firm performance.

In the regression analysis of table 3, the impact of network convergence on the operation cost of the digital culture industry is not statistically significant. However, the test of mediating effect in Tables 4 and 5 found that network convergence has a significant indirect impact on reducing the operating cost of the digital culture industry, and policy effect and capital effect play a partial mediating result between network convergence and operating cost digital culture industry. However, policy effect and capital effect are not parallel mediating effects but mediating chain effects. In-network convergence, the separate capital effect or separated capital effect could not reduce the operating cost of the digital culture industry. The impact of network convergence is that policy effect influences capital effect, and then capital effect influences the operation cost of the digital culture industry. The path of mediating impact is as follows; network converges $\rightarrow$ Policy effect $\rightarrow$ Capital effect $\rightarrow$ Operating cost.

\section{CONCLUSION}

It is concluded that the effect of network convergence on firm performance of the digital culture industry is not statistically significant in the regression analysis, and this effect also has no indirect impact on the test of mediating effect. In the regression model with firm performance as the dependent variable, only the operating costs of digital content companies significantly negatively affect strong performance. Therefore, it can be concluded that network convergence indirectly leads to the reduction of operating costs of the digital content companies, and the removal of operating expenses may improve the firm performance. There are three theoretical contributions to this study. First, this paper regards network convergence as a gradual development process rather than an overnight process, which is mentioned in this paper's model derivation and empirical research. The second is to draw lessons from the theories of institutional economics to put forward the policy effect and capital effect that were few mentioned formally in the past-related studies. Moreover, the empirical research of this paper drew that the significant indirect impact of network convergence on the operating cost of digital content companies is brought by mediating chain effect of these factors. All in all, the novelty of this paper is as follows. This paper tested the impact of progressive network 
convergence from the perspective of evolution. Most empirical studies adopted cross-sectional data to test the mediating effect, while this paper uses panel data. There is three research direction in the future. First, some frontier technologies such as A.I., which are related to network convergence, are also fundamental driving forces for the development of the digital content industry. Therefore the relationship among A.I., network convergence, and the digital content industry is an important research direction. Second, some theories of media convergence can be tried to study this question of this paper besides industrial network economics and related economics. At last, the reference of Chinese experience to Indonesia on network convergence and digital content industry is a good research field.

\section{REFERENCES}

Bardhan, I., Krishnan, V., \& Lin, S. (2013). Research note-business value of information technology: Testing the interaction effect of I.T. and R\&D on Tobin's Q. Information Systems Research, 24 (4), 1147-1161.

Brusoni, S., \& Pavitt, K. (2003). Problem solving and the co-ordination of innovative activities. The University of Sussex, SPRU Electronic Working Paper Series, 93.

Cao, S. F. (2015). The change of media industry driven by capital and policy. Science EO Technology for China's Mass Media. (9),86-91.

Chen, P. (2011). Upgrading strategy for T.V. content industry in triple-play environment. TV Research, (1), 17-20.

Francis, M., Thomas, A., Thompson, G., \& Rowlands, H. (September 9-11, 2009). Convergence and the digital culture industry: New business models and supply chain structures for a volatile new digital landscape. Logistics Research Network Annual Conference: Volatile and Fragile Supply Chains. Cardiff University.

Gao, C. (2014). Development of digital culture industry of China in the background of tri-network convergence. Business age, 23, 125-127.

Gao, D. (2013). Market structure and competitive behavior of digital culture industry under tri-network convergence. Master thesis of Southeast University.

Hacklin, F., Raurich, V., \& Marxt, C. (2005). Implications of technological convergence on innovation trajectories: The case of the ICT industry. International Journal of Innovation and Technology Management, 2(3), 313. 
Informasi, Vol. 51. No. 2. (2021), 195-226

330.

Hu, H. (2007). Network convergence: Services, applications, transport, and operations support. Wiley.

Ioannis, M. (2009). Information, telecommunication technologies and media convergence challenges: Perspectives on the creative content industries. VUB Press.

Iosifidis, P. (2002). Digital convergence: challenges for European regulation. The public, 9(3), 27-48.

Khalil, E. L. (1993). Economic behavior and institutions. International Review of Economics EF Finance, 2(4),429-432.

Kim, S. (2010). Research in convergence: A literature analysis. Journal of Research and Practice in Information Technology, 42(3), 191-205.

Lind, J. (2004). Convergence: History of term usage and lessons for firm strategists. Paper presented at the 15th Biennial ITS Conference.

Liu, C. (2013). Examining China's triple-network convergence plan: Regulatory challenges and policy recommendations. Government Information Quarterly, 30(1), 45-55.

McLuhan, M. (1964). Understanding media. Routledge.

Mi, L.J. (2015). Research review of tri-network convergence: From concept to operation. Editorial Friend, (1), 25-28.

Miyazaki, K., \& Giraldo, E. (2015). Innovation strategy and technological competence building to provide next-generation network and services through convergence-the case of NTT in Japan. Asian Journal of Technology Innovation, 23 (sup1), 74-92.

Moyer, S., \& Umar, A. (2001). The impact of network convergence on telecommunications software. IEEE Communications Magazine, 39 (1), $78-84$.

Nabli, M. K., Nugent, J. B. (2016). The new institutional economics and its applicability to development. World Development, 17(9),1333-1347.

Napoli, P. (2001). Foundations of communications policy: Principles and process in the regulation of electronic media. Cresskill, NJ: Hampton Press.

OVUM. (1999). Fixed-mobile convergence service integration and substitution.

Patel, V. (1992). Broadhand convergence: A view of the regulatory barriers. Telecommunications Policy, 16(2), 98-104. 
Qin, M. (2014). Network game: An important centre and pulling power of trinetwork convergence. Beauty and Times (Early), (7), 56-59.

Rong, H. (2014). Learning from foreign experience to push tri-network convergence of China. Private Science and Technology, (11), 224.

Rost, P., Boutaba, R., Doppler, K,, \& Gumaste, A. (2011). Recent advances in networks convergence. Computer Networks, Computer Networks, 55 (7), 1455-1458.

Shy, O. (2001). The economics of network industries, Cambridge University Press.

Song, D. (2014). Copyright protection strategies of digital music in tri-network convergence context. Publishing Research, (3), 61-63.

Stock, J. H., \& Watson, M. W. (2003). Instructional stata datasets for econometrics. Boston College Department of Economics.

Tang, X. D., \& Xiao, Y. F. (2013). Transition and upgrade of digital publishing in the tri-network convergence era. Press Circles, (4), 72-75.

The State Council. (February 20, 2010). The state council confirms the paths and schedule of tri-network convergence. Beijing Daily.

Tsai, H. H., Lee, H. Y., \& Yu, H. C. (2008). Developing the digital culture industry in Taiwan. Review of Policy Research, 25(2), 169-188.

Tu, W. Y. (September 18, 2012). Triple play is in full swing, and the content industry is the most impressive. Communication world weekly.

Whitt, R. S. (2004). A horizontal leap forward: Formulating a new communications public policy framework based on the network layers model. Federal Communications Law Journal, 56(3), 587.

Wu, R. W., \& Leung, G. K. (2012) Implementation of three network convergence in China: A new institutional analysis. Telecommunications Policy, 36(10-11), 955-965.

Wurgler, J. (2001). Financial market and the allocation of capital. Journal of Financial Economics, 58 (1), 187-214.

Yang, J. (2011). Study on venture capital and the development of digital publishing Industry. Peking University Master's Thesis.

Yong, G. J., \& So, Y. S. (2008). Structural equation model for effective CRM of digital culture industry. Expert Systems with Applications, 34 (1), 63-71. 
Informasi, Vol. 51. No. 2. (2021), 195-226 